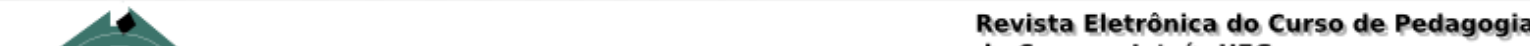 do Campus Jataí - UFG

\section{ÉTICA. Impactos na formação e atuação do professor contemporaneidade} na

\author{
Maria Aparecida Augusto Satto Vilela. Professora da Fundação \\ Educacional de Ituiutaba/Associada à UEMG, \\ cidasatto@hotmail.com \\ Lúcia Helena Moreira de Medeiros. Oliveira. Professora da \\ Universidade Federal de Goiás/CAJ·1hmmo.ufg@gmail.com
}

RESUMO: Este artigo tem como propósito analisar, subsidiado por uma pesquisa bibliográfica, o conceito de ética em duas obras relevantes: a primeira é Pedagogia da Autonomia, de Paulo Freire, e a segunda é Ética e Competência, de Terezinha Azeredo Rios. Os dois livros, pautados em pressupostos filosófico-educacionais, contribuem para a reflexão sobre os saberes e competências necessários à formação e atuação do educador, tendo em vista a sociedade e o período em que vivemos. De acordo com a análise empreendida, vislumbra-se o papel da ética freireana, pautada precisamente pela ação, pelo exemplo do professor, muito mais do que pelo seu discurso. Em Rios (2001), evidencia-se a necessidade do educador refletir sobre seus atos e os valores que os fundamentam e os da sociedade da qual faz parte, constituindo-se, desse modo, em um ser político. Os dois autores contribuem para se repensar a formação docente visto que um professor que fundamenta suas ações pela ética é mais solidário, crítico e vê o aluno como Outro, como ser humano de necessidades e desejos diferentes, mas não inferiores, aos seus.

PALAVRAS-CHAVE: Ética. Formação docente. Saberes do professor. Competências e Habilidades.

ABSTRACT This article aims to analyze, informed by a literature search, the concept of ethics in two important works: the first is Pedagogy of Autonomy of Paulo Freire, and the second is Ethics and Competence, Terezinha Azeredo Rios. The two books, guided by philosophical and educational assumptions, contribute to the reflection on the knowledge and skills required for training and performance of the educator, in view of the society and the time in which we live. According to this analysis, sees the role of Freire's ethics, precisely guided by action, by the example of the teacher, far more than by his speech. In Rios (2001), highlights the need for educators to reflect on their actions and values that underlie them and those that underlie the society they are part of, being thus in a political being. The two authors contribute to rethinking teacher education as a teacher who based their actions on ethics is more supportive, critical and sees the student as Other, as a human being needs and desires of different but not inferior, to their.

KEYWORDS: Ethics. Teacher Training. Knowledge of the teacher. Skills and Abilities. 


\section{Introdução}

Segundo os debates atuais no campo da educação, a escola deve formar profissionais competentes e compromissados com as transformações sócio-econômicas em que o mundo se insere. Neste caso, a escola e o professor passam a ter seus papéis ressignificados, ao produzir novos objetivos e prioridades e, desse modo, são "conduzidos" a formar um novo trabalhador, flexível, polivalente e atualizado, pressupondo, assim, mudanças no cotidiano escolar, sobretudo, na prática docente. $\mathrm{O}$ avanço tecnológico dos meios de comunicação e a informática, de certo modo, interferem no fazer pedagógico do professor. Entende-se que à escola e ao professor cabe a tarefa mais difícil e complexa que é a responsabilidade de formar pessoas capazes de aprender em um processo de mudanças contínuas, cujo fio condutor é a lógica de mercado. Entretanto, de forma quase paradoxal, precisamos desenvolver uma prática educativa que forme o aluno com autonomia e qualidade dentro dos princípios da ética e da solidariedade. A partir dessa reflexão, julgou-se relevante este estudo, no qual, propôs-se analisar a concepção de ética na última obra escrita por Paulo Freire, Pedagogia da Autonomia: saberes necessários à prática educativa, publicada em 1996, comparando-a aos pressupostos filosófico-educacionais apresentados por Terezinha Azêredo Rios, no livro Ética e Competência.

A escolha, como objeto de análise, das duas obras concentrou-se, de forma especial, em Pedagogia da Autonomia. No capítulo 1 - Não há docência sem discência, destacam-se nove saberes, dos quais analisou-se Ensinar exige estética e ética, Ensinar exige a corporeificação das palavras pelo exemplo, Ensinar exige risco, aceitação do novo e rejeição a discriminação, Ensinar exige respeito à autonomia do ser do educando. No capítulo 2, Ensinar não é transferir conhecimento, que possui nove saberes elencados por Freire, fez-se referência aos saberes Ensinar exige respeito à autonomia do ser do educando e Ensinar exige humildade, tolerância e luta em defesa dos direitos dos educadores. No último capítulo, Ensinar é uma especificidade humana, destacou-se Ensinar exige saber escutar. Na obra de Terezinha Rios, evidenciou-se o conceito de ética e as competências do professor.

\section{Análise comparativa: Pedagogia da Autonomia e Ética e Competência}

O estudo empreendido pautou-se pela análise da categoria ética a partir de alguns saberes dos professores apontados por Freire, e das competências necessárias à prática 
profissional apresentadas por Rios. Para Freire (2001, p.19) ensinar, na perspectiva da eticidade, é trabalhar "os conteúdos no quadro da rigorosidade do pensar certo, nega, como falsa, a fórmula farisaica do "faça o que mando e não o que eu faço"”.

Inicialmente, ao tratar da concepção de ética, é importante destacar como ela foi compreendida por Freire. Em um dos saberes Ensinar exige estética e ética o educador pernambucano destacou a importância da decência, pureza e coerência ao se referir à busca pela ética, visto que ela exige

Uma crítica permanente aos desvios fáceis com que somos tentados, às vezes ou quase sempre, a deixar dificuldades que os caminhos verdadeiros podem nos colocar. Mulheres e homens, seres histórico-sociais, nos tornamos capazes de comparar, de valorar, de intervir, de escolher, de decidir, de romper, por tudo isso, nos fizemos seres éticos. Só somos porque estamos sendo. Estar sendo é a condição, entre nós, para ser. Não é possível pensar os seres humanos longe, sequer, da ética, quanto mais fora dela. Estar longe ou pior, fora da ética, entre nós, mulheres e homens, é uma transgressão. É por isso que transformar a experiência educativa em puro treinamento técnico é amesquinhar o que há de fundamentalmente humano no exercício educativo: o seu caráter formador. (FREIRE, 1997, p.18-19)

O educador, segundo o autor, constrói-se ético na sua experiência educativa e, nesse sentido, a preparação puramente técnica não lhe permite formar-se como docente e, principalmente, como ser humano. Desse modo, reflete e age de forma correta e possibilita a aquisição desse comportamento a seus alunos também.

Nessa perspectiva, os demais saberes apresentados por Freire, dos quais serão destacados alguns neste texto, possibilitam a formação ética do professor que deve agir conforme o seu discurso e não ter uma prática diferente daquela que verbaliza. Sendo assim, Ensinar exige a corporeificação das palavras pelo exemplo:

Que podem pensar alunos sérios de um professor que, a dois semestres, falava com quase ardor sobre a necessidade da luta pela autonomia das classes populares e, dizem que não mudou, faz discurso pragmático contra os sonhos e pratica a transferência de saber do professor para o aluno?! Que dizer da professora que, de esquerda ontem, defendia a formação da classe trabalhadora e que, pragmática hoje, se satisfaz, curvada ao fatalismo neoliberal, com o puro treinamento do operário, insistindo, porém, que é progressista? (FREIRE, 1997, p.19)

Os questionamentos apresentados evidenciam a preocupação que todo educador deve possuir no processo de ensino-aprendizagem. Profissionais incoerentes e que não "pensam certo", trilhando o caminho certo, entenda-se ético, não podem cobrar uma conduta 
irrepreensível de seus alunos, visto que desdizem continuamente a sua própria argumentação. "É difícil, entre outras coisas, pela vigilância constante que temos de exercer sobre nós próprios para evitar os simplismos, as facilidades, as incoerências grosseiras" (FREIRE, 1997, p.28).

A questão ética parte do processo de reflexão sobre os valores e, portanto, um discurso coerente e uma conduta que incorporem esse pensar, no qual o diálogo seja ação constante nesse processo. Outro saber que evidencia a visão ética de Paulo Freire é Ensinar exige risco, aceitação do novo e rejeição a discriminação, ao destacar a questão do preconceito.

A prática preconceituosa de raça, de gênero ofende a substantividade do ser humano e nega radicalmente a democracia. Quão longe dela nos achamos quando vivemos a impunidade dos que matam meninos nas ruas, dos que assassinam camponeses que lutam por seus direitos, dos que discriminam os negros, dos que inferiorizam as mulheres. (FREIRE, 1997, p. 20)

Discutida e problematizada por muitos filósofos gregos a partir de Sócrates, a essência humana ou como Freire aponta sua substância, indica a preocupação que o educador deve ter ao ensinar. $\mathrm{O}$ aspecto ético, na formação e atuação do professor, requer o reconhecimento da existência do Outro, compreendido como um ser de direitos, independente de suas escolhas e opções pessoais, assim como de aparência e características genéticas.

O educador, dessa forma, é um profissional atento às mudanças e, portanto, compromete-se com o seu saber-fazer, com a aquisição de saberes por parte dos discentes que lhes permitam fazer valer seus direitos. Assim, professores e alunos aprendem, bem como percebem seu lugar no mundo como atores sociais.

Compreende-se, pelo exposto, a relevância do seguinte saber: Ensinar exige respeito à autonomia do ser do educando, pois segundo Freire (1997, p.35)

$\mathrm{O}$ respeito à autonomia e à dignidade de cada um é um imperativo ético e não um favor que podemos ou não conceder uns aos outros. Precisamente porque éticos podemos desrespeitar a rigorosidade da ética e resvalar para a sua negação, por isso é imprescindível deixar claro que a possibilidade do desvio ético não pode receber outra designação senão a de transgressão. $\mathrm{O}$ professor que desrespeita a curiosidade do educando, o seu gosto estético, a sua inquietude, a sua linguagem, mais precisamente, a sua sintaxe e a sua prosódia; o professor que ironiza o aluno, que minimiza, que manda que "ele se ponha em seu lugar" ao mais tênue sinal de sua rebeldia legitima, tanto quanto o professor que se exige do cumprimento de seu dever de ensinar, de estar respeitosamente presente à experiência formadora do educando, transgride os princípios fundamentalmente éticos de nossa existência. 
Mais uma vez, a eticidade é o fio condutor da reflexão freireana quanto aos saberes necessários à prática educativa. Ser ético, nessa perspectiva, não é errar jamais, mas ter o cuidado, utilizar a "justa medida", preocupar-se com o saber-fazer em sua prática educativa e, nesse sentido, com a formação discente, permitindo-lhe ser, também, agente no processo de ensino-aprendizagem, bem como na vida fora da escola. Ao invés de tolher a criticidade, o questionamento dos alunos, o educador os incentiva, favorecendo a existência de espaços em que o diálogo e a participação tornam-se frequentes.

Os docentes e os discentes devem ser atuantes, seres políticos que lutam frequentemente por seus direitos e dos grupos sociais dos quais faz parte. Dessa forma, os docentes precisam compreender que Ensinar exige humildade, tolerância e luta em defesa dos direitos dos educadores, saber presente no Capítulo 2, Ensinar não é transferir conhecimento.

O combate em favor da dignidade da prática docente é tão parte dela mesma quanto dela faz o respeito que o professor deve ter à identidade do educando, à sua pessoa, a seu direito de ser. Um dos piores males que o poder público vem fazendo a nós, no Brasil, historicamente, desde que a sociedade brasileira foi criada, é o de fazer muitos de nós correr o risco de, a custo de tanto descaso pela educação publica, existencialmente cansados, cair no indiferentismo fatalistamente cínico que leva ao cruzamento dos braços. 'Não há o que fazer' é o discurso acomodado que não podemos aceitar. (FREIRE, 1997, p.40)

A acomodação do professor não pode fundamentar o seu modo de pensar e agir. Fazse necessário que lute por sua valorização profissional e recupere sua condição de protagonista na sociedade em que está inserido, de forma que suas reivindicações tenham sentido. "A questão que se coloca, obviamente, não é parar de lutar, mas reconhecendo-se que a luta é uma categoria histórica, reinventar a forma também histórica de lutar" (FREIRE, 1997, p.40).

A reflexão sobre a conjuntura brasileira revela a necessidade de se identificar quem são os docentes que atuam nas escolas, que função ocupam no cenário brasileiro e que sonhos e desejos acalentam, tendo em vista o quadro atual da profissão, em relação às condições de trabalho, à formação dos professores e às políticas públicas existentes, pautadas na lógica mercantil, que não conseguiram solucionar aspectos referentes à valorização da profissão docente e de suas perspectivas futuras.

Por fim, como último e essencial saber analisado, destaca-se Ensinar exige saber escutar: 
Se, na verdade, o sonho que nos anima é democrático e solidário, não é falando dos outros, de cima para baixo, sobretudo, como se fôssemos os portadores da verdade a ser transmitida aos demais, que aprendemos a escutar, mas é escutando que aprendemos a falar com eles. Somente quem escuta paciente e criticamente o outro, fala com ele, mesmo que, em certas condições, precise de falar a ele. (FREIRE, 1997, p.71)

Nesse sentido, entende-se que um bom orador é aquele que é um ouvinte atento, que se procura em entender a posição teórica-conceitual ou opinativa do Outro e não apenas pressupõe a certeza do seu saber. "É preciso, porém, que quem tem o que dizer saiba, sem sombra de dúvida, não ser o único ou a única a ter o que dizer" (FREIRE, 1997, p.73). Pressupõe-se que esse professor tem e põe em prática seu discurso democrático, de forma que as relações sejam horizontais e não verticalizadas, hierarquizadas, pois "ao escutar aprendo a falar com o educando". As relações concebidas dessa forma são estabelecidas pela comunhão e pautadas por uma vivência ética.

Assim como Freire, Rios também analisou a relevância de uma concepção ética para a formação e atuação do professor. Em sua obra Ética e Competência compreende "ética como espaço da reflexão filosófica que se define como reflexão crítica, sistemática, sobre a presença dos valores na ação humana" (RIOS, 2001, p.19). Com base no que a autora destaca como ética, verifica-se que além de ser campo de estudo da filosofia, ela é compreendida como análise sobre a axiologia humana. Desse modo, ser ético é repensar os valores, a moralidade que pauta as suas ações, constituindo-se como humano. "A ética procura o fundamento do valor que norteia o comportamento humano, partindo da historicidade presente nos valores" (RIOS, 2001, p.24).

Os valores morais são constituídos em cada momento histórico, determinando o que é certo ou errado, bom ou mau Por isso, ao referir-se à ética, é relevante analisar o contexto histórico-social e cultural das regras e normas morais em estudo.

Rios (2001) afirma que para compreender a educação, é preciso conhecer a conjuntura da qual ela faz parte, configurando suas singularidades. Portanto, o conhecimento das questões culturais que envolvem a educação a ser analisada, como a brasileira, por exemplo, assim como seus aspectos políticos permitem vislumbrar as questões ideológicas e dialéticas que a envolvem, como a "autonomia relativa" da escola, bem como a dimensão política da educação, o que interessa à análise de Rios, apesar da dimensão técnica existente.

Os conteúdos e técnicas não são absolutamente elementos neutros. Eles são selecionados, transmitidos e transformados em função de determinados interesses existentes na sociedade. O papel político da educação se revela na 
medida em que ele se cumpre sempre na perspectiva de determinado interesse. (RIOS, 2001, p.42-43)

Um professor despolitizado, dessa forma, está a serviço de uma ética em que prevalecem valores que não contribuem para o fortalecimento da solidariedade, do respeito e da igualdade, motivando a preservação dos valores da sociedade capitalista, de individualismo, hierarquia e competição.

A partir dessa perspectiva, compreende-se a função do educador ao articular no espaço escolar duas dimensões (técnica e política), por meio de uma terceira dimensão: a ética.

Ao analisar as competências desse educador, Rios (2001, p.46) aponta o que é competência: o "saber fazer bem". A autora, ao analisar o saber fazer bem, identifica tanto o aspecto técnico (saber fazer) relacionado à dimensão política, ao designar um valor à atuação profissional, o bem. Tendo em vista que o termo bem se refere ainda à questão moral, a dimensão ética perpassa o trabalho do professor. Nesse sentido, a articulação entre técnica e política pressupõe "Que é preciso recuperar no próprio caráter dialético da prática educativa a articulação entre os dois pólos da competência, e me parece fértil esse caminho que passa pela ética” (RIOS, 2001, p.48).

É importante que o educador compreenda de forma crítica o que é "fazer bem", visto que não significa agir apenas de forma bondosa ou de relacionar-se bem com os alunos. Nesse sentido, é relevante que o professor analise criticamente sua ação para que não se paute em uma "prática educativa apenas moral, ou na visão equivocada de um compromisso que se sustenta na afetividade, na espontaneidade" (RIOS, 2001, p.49). Sendo assim, o educador precisa entender a "dimensão ética embutida na dimensão política e técnica" (RIOS, 2001, p.51).

Um docente sem a compreensão de que a política faz parte de sua atuação, torna-se despolitizado. O educador precisa ter responsabilidade, compromisso, sabendo de sua importância na intervenção da sociedade e, principalmente, na vida de seus alunos. O compromisso requer adesão, querer, "a partir da escolha do sujeito" (RIOS, 2001, p.57), de seu poder, como campo de possibilidades e limites, que proporciona a realização de mudanças.

Outro aspecto importante é o da subjetividade que não é sinônimo de individualidade, mas sim da relação do eu com o Outro; portanto, algo que contribui para a socialização dos seres. Essa socialização também se dá por meio da propagação do conhecimento como 
"resultado de relações sociais dos indivíduos, [e] tem indiscutivelmente uma conotação de valor, ainda que se revista de objetividade" (RIOS, 2001, p.55-56).

Pelo exposto, o docente será capaz de ter essas competências se tiver consciência de sua ação, por meio do entendimento crítico do meio em que vive e atua. A ação consciente leva à intencionalidade de sua prática educativa e não mera reprodução de modismos teóricos e epistemológicos, dentre outros. Essas considerações de Rios apontam para um projeto de formação de professores em que a atuação mediadora é a mais adequada a esse momento.

Assim, professor e aluno são sujeitos conhecedores, e a tarefa do professor é estabelecer o diálogo do aluno com o real, não com ele, professor, especificamente. Porque é por meio da relação professor-aluno que o objeto que é o mundo é apreendido, compreendido e alterado, numa relação que é fundamental - a relação aluno-mundo - propiciada pela relação professormundo. (RIOS, 2001, p.70)

\section{Considerações Finais}

Tendo em vista a conjuntura atual da educação escolar e os pressupostos teóricos defendidos por Freire e Rios, é preciso repensar a formação do professor. Segundo Freire é necessário que ao ensinar o professor favoreça a comunhão, o diálogo, a compreensão das emoções e sentimentos, de forma autêntica, em que ambos (docente e discente) possam aprender. Ao longo desse processo, como apontam Freire e Rios, a ética perpassa as ações docentes, tendo a escola e o mundo como espaço de vivência e convivência.

No suporte, os comportamentos dos indivíduos têm sua explicação muito mais na espécie a que pertencem os indivíduos do que neles mesmos. Faltalhes liberdade de opção. Por isso, não se fala em ética entre os elefantes. (FREIRE, 1997, p.29)

Nesse sentido, a prática formadora ética tem papel de excelência na proposta freireana, assim como é possível identificá-la em Rios. Esta autora afirma que uma atuação ética não se vincula a uma atitude em que o sentimentalismo e a afetividade se sobreponham a outros valores. Freire destaca o papel do afeto e do sentimento do professor em relação ao aluno, mas isso não pode se colocar acima do saber crítico e consciente do educador.

Outra questão similar entre os dois autores é a dimensão política que deve fazer parte da atitude dos docentes, contribuindo para a intervenção social, transformando o espaço ao 
seu redor. Isso favorece a desnaturalização da prática docente, que não se revela em missão, dom ou vocação, mas sim de circunstâncias histórico-sociais.

A percepção de que "Só os seres que se tornam éticos podem romper com a ética" (FREIRE, 1997, p.30) denuncia o caráter de inacabamento e incompletude que permite ao homem um eterno vir a ser, em uma contínua mudança que nem sempre tem um resultado melhor do que a situação anterior. Ao analisar essa questão, compreende-se a relevância de temas como respeito, solidariedade e inclusão, principalmente na sociedade brasileira atual.

Por isso, deixamos aqui o debate em aberto, com a seguinte frase de Freire (1997, p.35):

Não me venha com justificativas genéticas, sociológicas ou históricas ou filosóficas para explicar a superioridade da branquitude sobre negritude, dos homens sobre as mulheres, dos patrões sobre os empregados. Qualquer discriminação é imoral e lutar contra ela é um dever, por mais que se reconheça a força dos condicionamentos a enfrentar.

\section{Referências bibliográficas}

FREIRE, Paulo. Pedagogia da autonomia: saberes necessários à prática educativa. São Paulo: Paz e Terra, 1997.

RIOS, Terezinha Azeredo. Ética e competência. 11 ed. São Paulo: Cortez, 2001. 